\title{
Case study - SIMEC Mining Big Baron Pit successful tailings dewatering and management using WaterShed polymer
}

\author{
F Verdoorn SIMEC Mining, Australia \\ B Owens SIMEC Mining, Australia \\ K Gibbs Nalco Water, Australia
}

\begin{abstract}
In 2012, SIMEC Mining commissioned a haematite ore beneficiation plant (OBP) at the Iron Baron mine site in the North Middleback Ranges of South Australia, to upgrade low and medium grade waste dumps. The tailings discharge strategy was to convert existing previously mined pits into in-pit tailings storage facilities (TSF). Geotechnical assessments of the Big Baron Pit identified cracking in the base and walls. However, it was predicted that these cracks would seal within the first three to six months. Hence it was recommended that the pit could be used for in-pit tailings storage.

During the first six months of tailings deposition into the Big Baron Pit, there was no evidence of beach formation or solids/liquid separation and about $60 \%$ of the TSF volume was lost due to potential seepage and evaporation. The groundwater monitor bores surrounding the pit showed a steep increase in the rate of rise which was a concern.

The potential environmental impacts of the rising groundwater levels on native vegetation was unacceptable and the inability to recover any water from the tailings for reuse in the plant became a serious threat to sustainability of the operations. This necessitated an option investigation study to identify a technology to assist in rapid solids/water separation and subsequent sealing of the base of the pit.

A conceptual design for a polymer tailings dewatering application was developed in collaboration with Nalco Water; dosing commenced in March 2013. Within the first two days clear water was present at the decants and the dewatered solids started to form a well-defined beach.

Water extraction from the decant started within the first week, indicating the cracks were sealing as the solids settled and compacted. Survey data also indicated that the volume of the solids in the TSF started to increase accordingly. The reclaimed water from the decant was initially used for dust suppression until quality monitoring determined it was suitable for chemical make-up and use in the plant.

During the first year of application, an average of 63\% of the water entrapped in the tailings was recovered back into the plant. This reclaimed water is a direct replacement for purchased South Australian government water, thus saving on fresh water, which cost approximately AUD $3.50 / \mathrm{m}^{3}$ at that stage.

Due to the success of the Big Baron Pit application, the Nalco WaterShed program has been extended to other applications throughout SIMEC Mining Operations including our large above ground TSF at Iron Duke. All applications have provided excellent results with water recovery, solids consolidation and increased storage capacity.

Knowledge gained from the use of this technology has greatly assisted SIMEC Mining with its onsite water and fine tailings management and process efficiency improvements. Nalco WaterShed technology has played an integral part in the conversion of the above-ground TSF at Iron Duke from dual point discharge to a perimeter discharged central decant (PDCD) design, thus allowing to resolve groundwater management and construction issues and ultimately ensure operational security.
\end{abstract}

Keywords: WaterShed, polymer, tailings management, water recovery 


\section{Introduction}

SIMEC Mining is a large mining company based in South Australia. Mining is carried out in the Middleback Ranges approximately $60 \mathrm{~km}$ from the Whyalla township. The company is an exporter of haematite iron ore and supplies magnetite iron ore feed to Liberty OneSteel, an integrated steel works in Whyalla. SIMEC Mining and Liberty OneSteel is part of the GFG Alliance Australia.

Currently, SIMEC Mining operates in three mining regions with multiple pits - Iron Duchess, Iron Knight, Iron Duke, Iron Magnet, Iron Baron and Iron Chieftain (Figure 1).
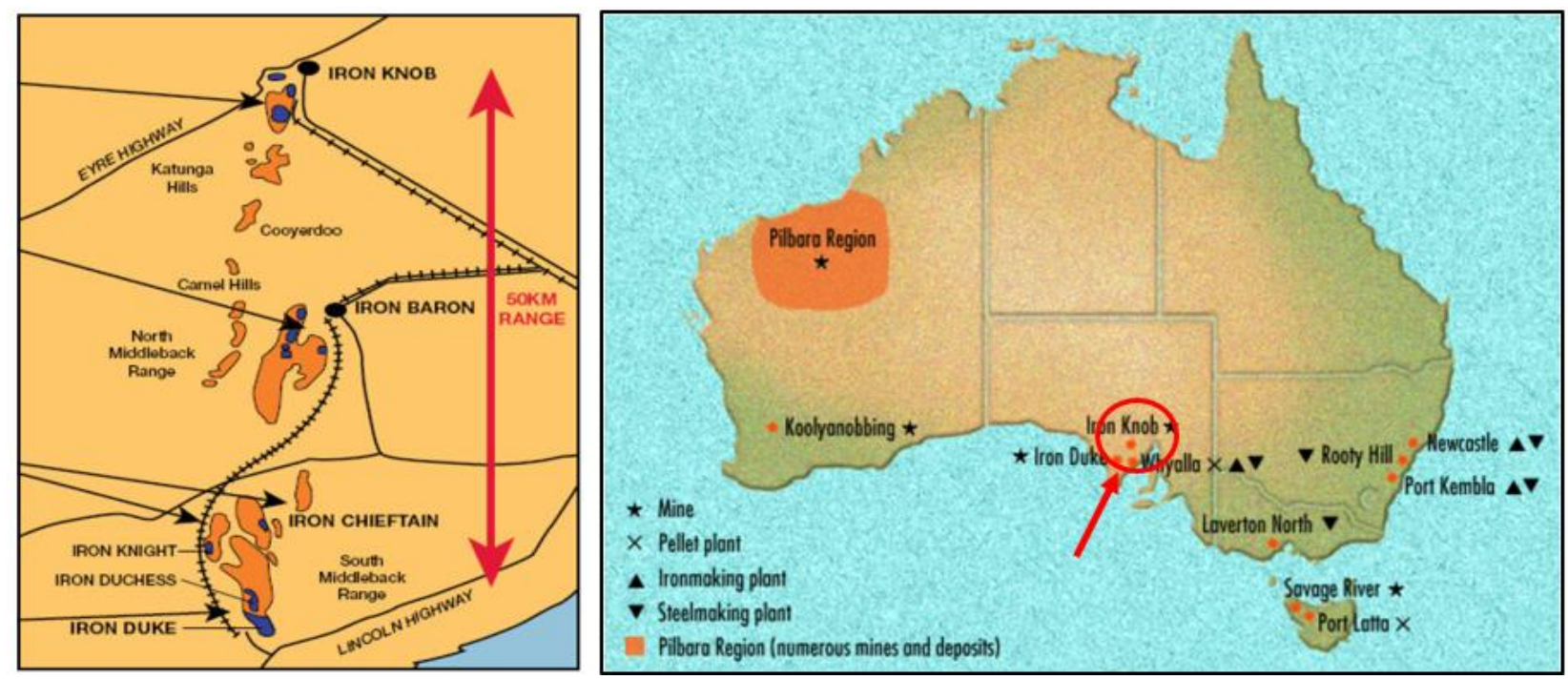

Figure 1 SIMEC's Eyre Peninsula mining areas

In 2012, SIMEC Mining commissioned a haematite ore beneficiation plant (OBP) at the Iron Baron mine site to upgrade low and medium grade waste dumps. The tailings discharge strategy was to convert existing previously mined pits into in-pit tailings storage facilities (TSF). Additionally, it was important that SIMEC Mining recovered as much of the entrained water in the tailings as possible for use back in the process to offset fresh water purchases.

This paper provides a case study surrounding activities at the Big Baron Pit tailings disposal area with respect to the problems that were encountered and how these issues were resolved using Nalco WaterShed polymer as well as the flow-on benefits to other areas of SIMEC's operations.

Also note that this successful case history resulted from close collaboration between SIMEC Mining staff with their mining experience and Nalco Water engineers with extensive experience in tailings treatment with polymers to develop a simple, cost-effective and operationally practical solution to the problems encountered at the Big Baron Pit.

\section{Problem analysis and data}

The primary issues with discharging untreated OBP tailings to the Big Baron Pit were:

- The business case for discharging tailings into the Big Baron Pit was built on the premise that water trapped in the tailings could be recovered to positively impact on SIMEC Operations Global Water Balance. No water was being released from the slurry or recovered for re-use with the existing plant configuration.

- As the pit had identified fault lines, this permitted potential loss of water to escape into the aquifer which could impact the water table.

- The quality of any water that could ultimately be extracted needed to be such that it could be used within the OBP, thus offsetting the need to purchase water from an outside source. 


\subsection{Tailings and water - where is it all going?}

With the introduction of the OBP, tailings had to be disposed of within the boundaries of the mining lease, and in-pit disposal of tailings was agreed upon as the best way forward after assessment of alternative solution viability, cost and safety considerations. The existing voids at the Iron Baron mine provided an ideal location to discharge the tailings as they required minimal capital injection since the pits were already established. They did require additional pipework for depositing the tailings and recovering the decant water back to the processing plant.

When the OBP began operation, tailings from the thickener underflow at $44 \%$ solids were pumped using multi-stage pumping several kilometres to the Big Baron Pit.

After several months of monitoring of the Big Baron Pit, it was apparent that very little water was being released from the slurry and that it was lost to evaporation and/or seepage. Tracking the pit capacity based on the volume of tailings deposited indicated that the pit level was not rising as fast as expected. The plant continued to deposit tailings into the Big Baron Pit and recorded the volume deposited versus the volume retained and the results were worse than anticipated. Using these results and some simple mass balances, knowing the percent solids and dry tailings mass, flow rate, etc., it was discovered that if it was only the water escaping then there should be more volume retained. This was not the case, so it was postulated that potentially some of the fine solids that are suspended in the tailings were escaping with the water.

Figure 2 shows this relationship (Owens 2013). The $x$ axis shows the volume of tailings retained and the $y$ axis shows the volume of tailings deposited into the pit. The orange line represents $100 \%$ retention.

\section{Big Baron Level Measurements from 5 July to 1 November}

\section{2}

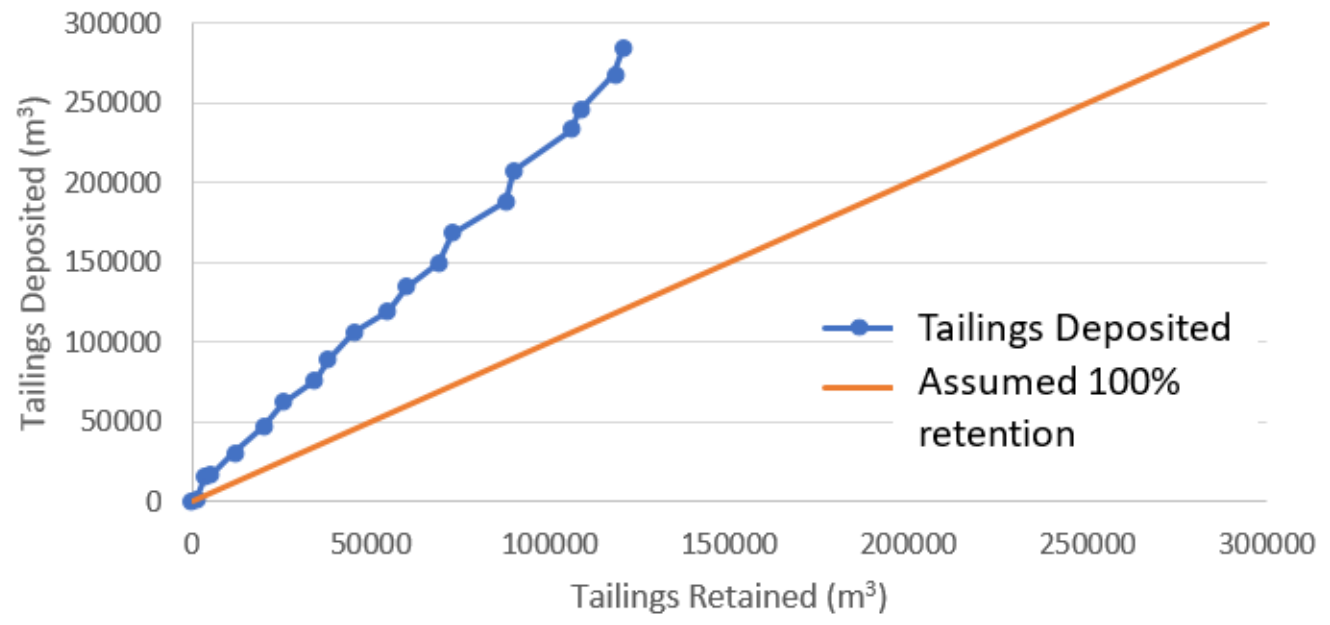

Figure 2 Volume retained in-pit late 2012 (before polymer trial)

Table 1 provides an overview of the tailings make-up being sent to the Big Baron Pit. There is a large quantity of fines, with over $60 \%$ being less than 38 microns. This high fine proportion potentially allows for easy movement of solids through faults and fissures, thus providing the potential to escape. 
Table 1 Big Baron OBP tailings assay and sizing analysis (60\%+ less than 38 micron)

\begin{tabular}{lllll}
\hline Size distribution & & \multicolumn{3}{c}{ Tailings assay } \\
Fraction & Mass $(\mathrm{gm})$ & $\%$ & & $\%$ \\
\hline$+1.180 \mathrm{~mm}$ & 11.4 & 1.6 & $\mathrm{Fe}$ & 37.9 \\
$-1.180+1.00 \mathrm{~mm}$ & 7.3 & 1.0 & $\mathrm{SiO}_{2}$ & 21.1 \\
$-1.100+0.850 \mathrm{~mm}$ & 6.4 & 0.9 & $\mathrm{Al}_{2} \mathrm{O}_{3}$ & 13.8 \\
$-0.850+0.600 \mathrm{~mm}$ & 16.8 & 2.3 & $\mathrm{TiO}_{2}$ & 1.0 \\
$-0.600+0.425 \mathrm{~mm}$ & 18.2 & 2.5 & $\mathrm{MnO}$ & 1.0 \\
$-0.425+0.300 \mathrm{~mm}$ & 20.1 & 2.8 & $\mathrm{CaO}$ & 0.4 \\
$-0.300+0.212 \mathrm{~mm}$ & 19.8 & 2.7 & $\mathrm{P}$ & 0.1 \\
$-0.212+0.150 \mathrm{~mm}$ & 23.7 & 3.3 & $\mathrm{SiO}_{2}$ & 0.1 \\
$-0.150+0.106 \mathrm{~mm}$ & 25.6 & 3.5 & $\mathrm{MgO}$ & 1.1 \\
$-0.106+0.075 \mathrm{~mm}$ & 27.9 & 3.8 & $\mathrm{~K}_{2} \mathrm{O}$ & 0.3 \\
$-0.075+0.063 \mathrm{~mm}$ & 21.7 & 3.0 & $\mathrm{Na}_{2} \mathrm{O}$ & 0.1 \\
$-0.063+0.053 \mathrm{~mm}$ & 28.1 & 3.9 & $\mathrm{LOI}$ & 6.7 \\
$-0.053+0.045 \mathrm{~mm}$ & 20.3 & 2.8 & - & - \\
$-0.045+0.038 \mathrm{~mm}$ & 21 & 2.9 & - & - \\
$-0.038 \mathrm{~mm}$ & 460.3 & 63.2 & - & - \\
Total & 728.6 & 100.0 & - & - \\
\hline
\end{tabular}

The plant was losing fine solids and water by seepage and evaporation and not recovering any decant at all to offset the cost of purchasing water from a limited-supply outside source. This had further implications of seriously impacting operational licences if groundwater rose past agreed maximum levels. It was at this stage that the search for a realistic, cost-effective and operationally practical solution to the problem was sought.

A geochemical assessment of a sample of the tailings produced at the ore beneficiation plant indicated that the tailings stream (both solids and liquids) should be geochemically benign and pose no constraints for the operation and decommissioning of an in-pit TSF. The assessment also deemed there to be no major failures identified on the northern, western and eastern walls of the Big Baron Pit. These walls are the main walls of concern. There were some small localised failures noted at various locations along the eastern wall. These locations were deemed not to be influential on the integrity of the eastern wall. There were erosion channels noticed on the western wall due to surface water runoff. These were not to be of concern. 
Figure 3 shows typical fissures and faults located along the eastern wall.

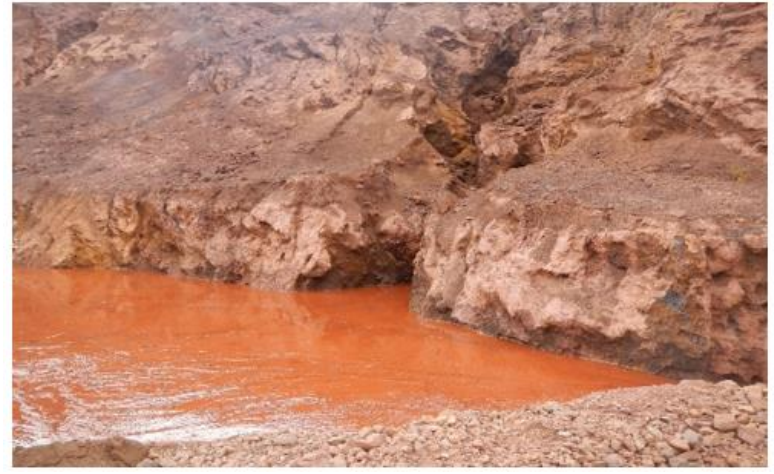

(a)

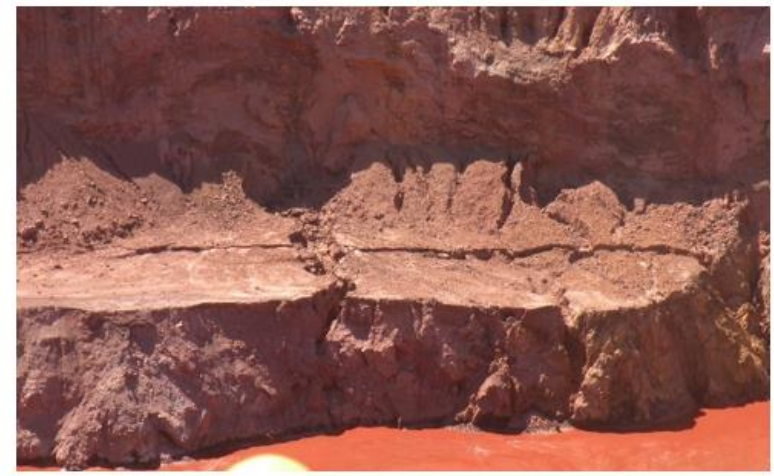

(b)

Figure 3 Big Baron Pit features. (a) Picture taken August 2012 which shows one of these fissures from ground level, a potential area for seepage; and, (b) Picture taken December 2012 of north-south fault line, another potential area for seepage

Figure 4 shows no free water separation from tailings deposited prior to treatment.

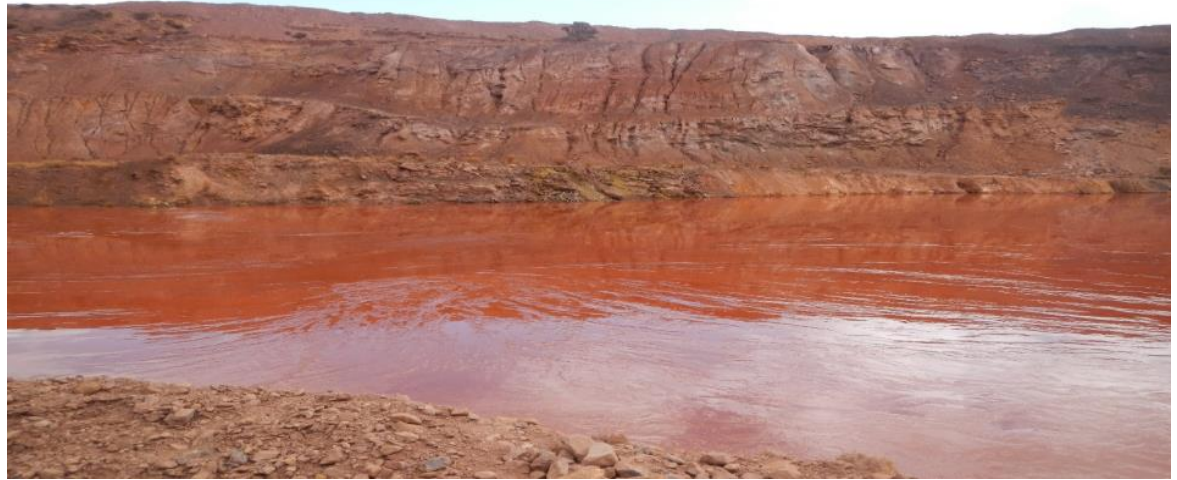

Figure 4 Big Baron Pit lack of solids/liquid separation

\subsection{Monitoring bore levels}

The bore levels are typically monitored by SIMEC Mining's environmental department at the start of each month. This provided some initial data to work from. Figure 5 shows data from May 2012 to September 2013. The area indicated shows the period in which the trial took place. The northern and western monitoring bores (Figure 6) continued to increase at the same rate as prior to the polymer treatment. The southern bore, which is located at the end of the pit where the decant water accumulates, can be seen to increase at a higher rate than prior to the trial. This was to be expected as it was anticipated the pit was not fully sealed prior to WaterShed polymer treatment (Owens 2013). 
Bore Levels

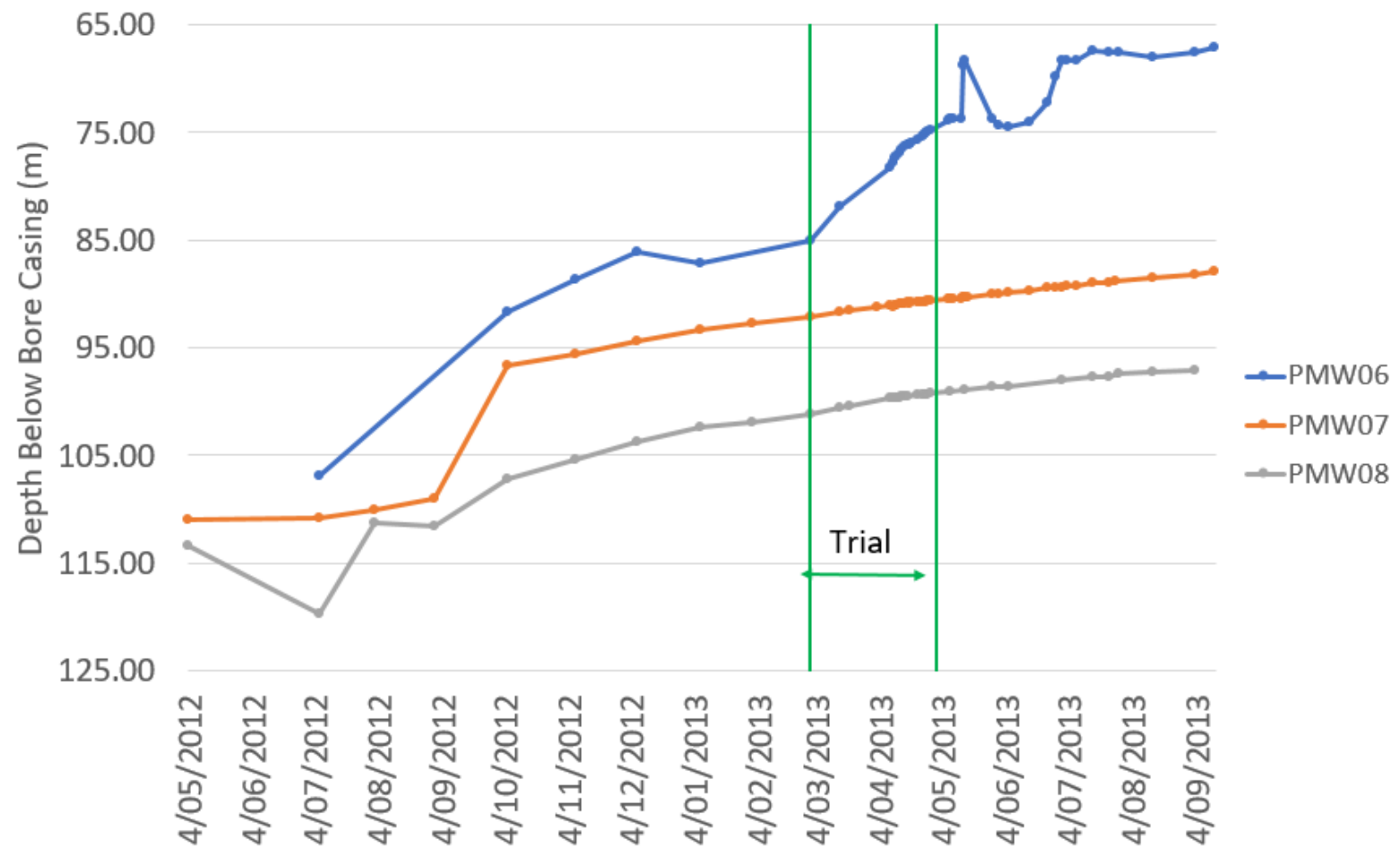

Figure 5 Levels before, during and after the initial trial period

\section{Monitoring Bore Locations}

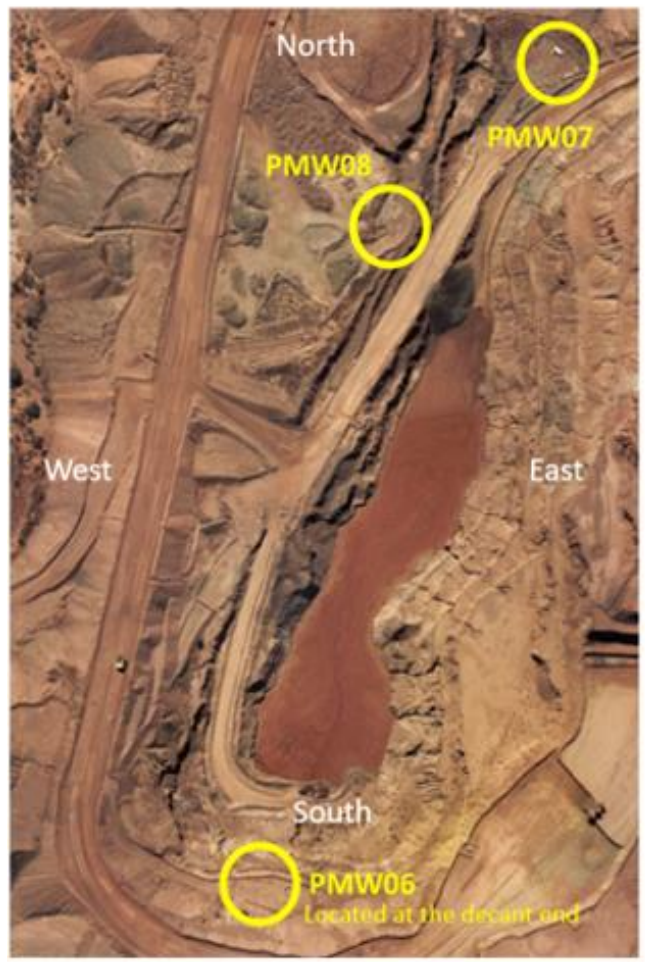

(a)

\section{Decant Tower Design}
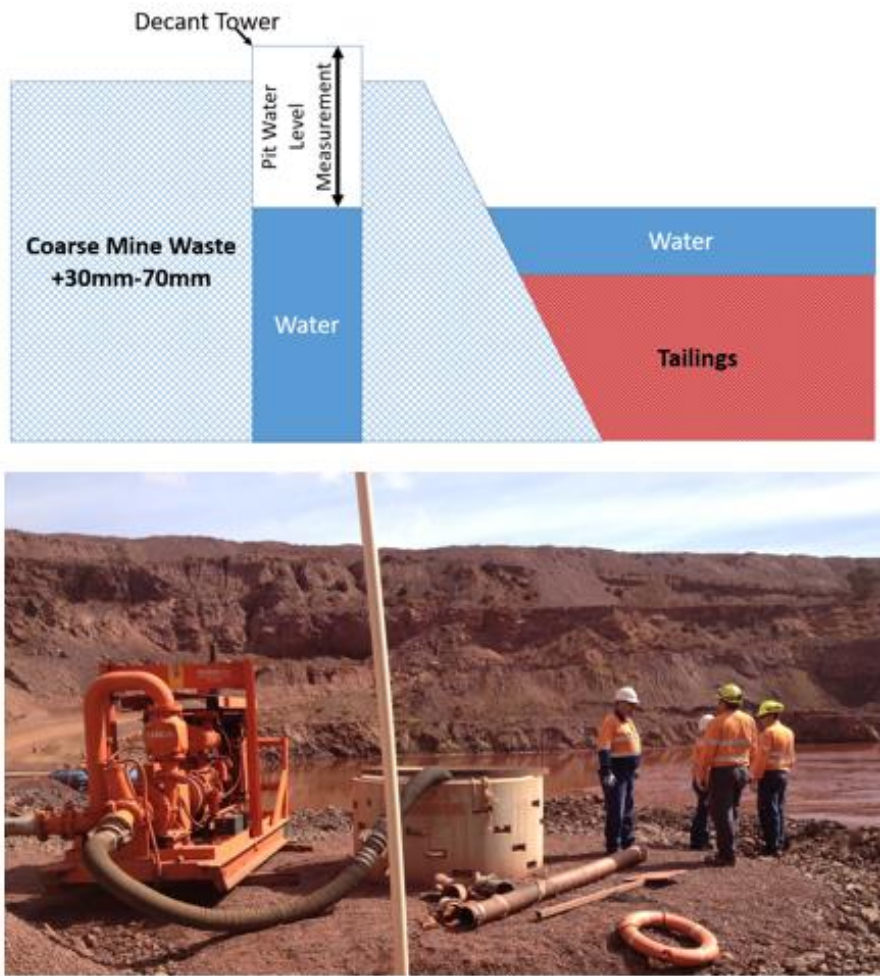

(b)

Figure 6 Monitoring bore locations and decant structure. (a) Monitoring bore locations; and, (b) decant tower design 


\subsection{Impact of returning recovered decant water to the process}

Figure 7 clearly shows that the fresh water make-up addition to the plant is approximately $120 \mathrm{~m}^{3} / \mathrm{hr}$ when the plant is running until the recovered decant water is introduced to the plant (red line) at approximately $60 \mathrm{~m}^{3} / \mathrm{hr}$. The fresh water addition drops straight away to approximately $60 \mathrm{~m}^{3} / \mathrm{hr}$, which shows a direct relationship with the recovered water. This recovered decant water is approximately $63 \%$ of the available water which was discharged as part of the slurry (Owens 2013).

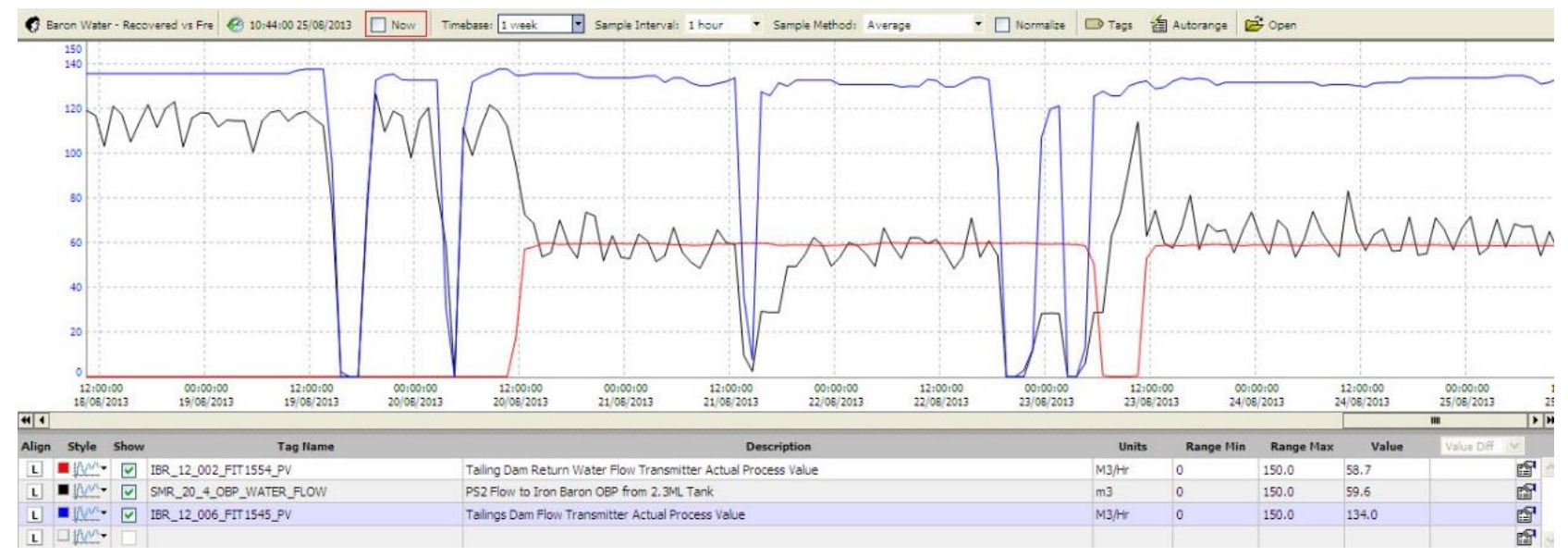

Figure 7 Trends of water and tailings flows at Iron Baron (August 2013)

\section{$2.4 \quad$ Water quality}

Since no decant water was available prior to commencing of polymer make-up, water was sourced from the Prince Pit as dilution water for the chemical dosing.

Table 2 shows the results of the water quality for the Big Baron Pit as well as the Prince Pit.

The Prince Pit water starts with a high conductivity and total dissolved solids. This can then be seen to have a flow-on effect to the Big Baron water as it too started with relatively high values for conductivity and total dissolved solids. The conductivity and total dissolved solids (TDS) can be seen to drop steadily over the course of the trial. This was expected as the process water that makes up the tailings was of much better quality than the water in the Prince Pit. During the trial, the recovered water was being deposited into the Prince Pit, diluting the Prince Pit water which feeds the dosing equipment (Owens 2013).

Towards the end of the trial, there were some results which indicated a higher quality water was recovered from the Big Baron Pit than was in the process water tank. This was a good outcome and confirmed that the recovered water from WaterShed polymer treatment was very acceptable for ongoing use in the plant. 
Table 2 Water quality - Big Baron and Prince Pits

\begin{tabular}{|c|c|c|c|c|c|c|c|c|}
\hline \multirow[b]{2}{*}{ Date } & \multicolumn{2}{|c|}{ Big Baron Pit } & \multirow[b]{2}{*}{$\mathrm{C}(\mathrm{uS} / \mathrm{cm})$} & \multirow[b]{2}{*}{ TDS (ppm) } & \multicolumn{2}{|c|}{ Prince Pit } & \multirow[b]{2}{*}{$\mathrm{C}(\mathrm{uS} / \mathrm{cm})$} & \multirow[b]{2}{*}{ TDS (ppm) } \\
\hline & $\mathrm{pH}$ & $\mathrm{T}\left({ }^{\circ} \mathrm{C}\right)$ & & & $\mathrm{pH}$ & $\mathrm{T}\left({ }^{\circ} \mathrm{C}\right)$ & & \\
\hline $17 / 03 / 2013$ & - & - & - & - & 7.8 & - & 9,361 & - \\
\hline $18 / 03 / 2013$ & 7.22 & 23.2 & 8,244 & 6,721 & 7.75 & - & 9,328 & - \\
\hline $19 / 03 / 2013$ & - & - & - & - & 7.72 & 25 & 9,118 & 7,530 \\
\hline 20/03/2013 & - & - & - & - & 7.72 & 23.1 & 9,235 & 7,637 \\
\hline $21 / 03 / 2013$ & 7.39 & 23.5 & 8,387 & 6,852 & 7.83 & 22.7 & 9,285 & 7,681 \\
\hline $22 / 03 / 2013$ & 7.49 & 21.7 & 8,297 & 6,791 & 7.89 & 20.2 & 9,312 & 7,738 \\
\hline $23 / 03 / 2013$ & 7.71 & 20.3 & 7,920 & 6,478 & 7.77 & 21.4 & 9,293 & 7,703 \\
\hline 24/03/2013 & 7.22 & 20.6 & 8,042 & 6,582 & 7.81 & 22.1 & 9,271 & 7,666 \\
\hline $25 / 03 / 2013$ & 7.59 & 21.5 & 7,960 & 6,491 & 7.69 & 20.8 & 9,287 & 7,706 \\
\hline $26 / 03 / 2013$ & - & - & - & - & 7.91 & 23.9 & 9,303 & 7,677 \\
\hline 08/04/2013 & 6.84 & 22.6 & 8,244 & 6,737 & 7.65 & 22.5 & 8,514 & 6,970 \\
\hline 09/04/2013 & - & - & - & - & 7.73 & 19.9 & 8,582 & 7,077 \\
\hline 09/04/2013 & 7.28 & 17.2 & 8,148 & 6,709 & - & - & - & - \\
\hline $10 / 04 / 2013$ & 7.38 & 20.7 & 7,522 & 6,100 & 7.76 & 20.7 & 8,572 & 7,054 \\
\hline $11 / 04 / 2013$ & 6.66 & 20.7 & 7,189 & 5,793 & 7.75 & 24.3 & 8,486 & 6,897 \\
\hline $12 / 04 / 2013$ & 7.35 & 25.4 & 7,363 & 5,909 & 7.73 & 23.8 & 8,416 & 6,879 \\
\hline $13 / 04 / 2013$ & 7.09 & 20.8 & 7,582 & 6,151 & 7.06 & 21.6 & 8,460 & 6,929 \\
\hline $14 / 04 / 2013$ & 6.61 & 22.8 & 7,468 & 6,025 & 7.59 & 23.4 & 8,350 & 6,813 \\
\hline $15 / 04 / 2013$ & 7.25 & 19.6 & 7,418 & 6,025 & 7.6 & 20.4 & 8,409 & 6,911 \\
\hline $16 / 04 / 2013$ & 7.25 & 17.7 & 7,439 & 6,052 & 7.72 & 19.2 & 8,321 & 6,846 \\
\hline $17 / 04 / 2013$ & 6.7 & 16.2 & 7,021 & 5,684 & 7.31 & 18.2 & 8,340 & 6,880 \\
\hline $18 / 04 / 2013$ & 6.5 & 24.5 & 7,300 & 5,846 & - & - & - & - \\
\hline $19 / 04 / 2013$ & 7.42 & 16.5 & 6,681 & 5,384 & 7.68 & 18.3 & 8,259 & 6,802 \\
\hline 20/04/2013 & 6.84 & 19.7 & 7,267 & 5,887 & 7.82 & 16.4 & 8,290 & 6,832 \\
\hline $22 / 04 / 2013$ & 7.35 & 20.2 & 7,294 & 5,905 & 7.97 & 18.7 & 8,135 & 6,684 \\
\hline $23 / 04 / 2013$ & 6.97 & 19.6 & 7,320 & 5,932 & 7.7 & 19.7 & 8,001 & 6,544 \\
\hline $24 / 04 / 2013$ & 7.16 & 17.3 & 7,227 & 5,869 & 7.72 & 18.8 & 8,122 & 6,668 \\
\hline $25 / 04 / 2013$ & 7.11 & 16.3 & 7,145 & 5,801 & 7.62 & 18.3 & 8,062 & 6,616 \\
\hline $26 / 04 / 2013$ & 7.28 & 18.4 & 7,081 & 5,723 & 7.71 & 18.1 & 8,082 & 6,642 \\
\hline $27 / 04 / 2013$ & 7.3 & 17.2 & 6,081 & 4,858 & 7.78 & 18 & 8,080 & 6,637 \\
\hline 28/04/2013 & - & - & - & - & 7.83 & 18.2 & 8,059 & 6,618 \\
\hline $02 / 05 / 2013$ & 6.78 & 18.4 & 4,729 & 3,677 & - & - & - & - \\
\hline
\end{tabular}




\section{$3 \quad$ WaterShed polymer trial progress and outcomes}

\subsection{Phase one - lab testing}

Significant lab testing and process modelling was carried out to establish the correct treatment program and the most effective application strategy to meet the ultimate trial objectives (Bennett 2011).

The full detail of this preliminary work will not be discussed in this paper as the objective is to relay actual plant results and performance against objectives that have the potential to help other operators in their efforts to solve 'here and now' plant problems. Consulting services are available to assist with specific client needs regarding the use of this technology.

The following photos (Figure 8) demonstrate the WaterShed polymer technical capability to separate solids from water in bench-scale test work.

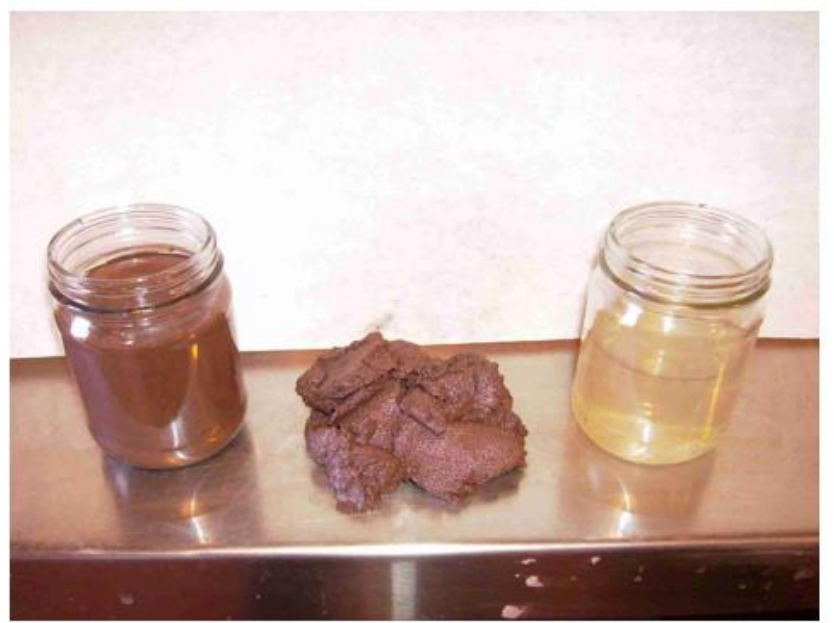

(a)

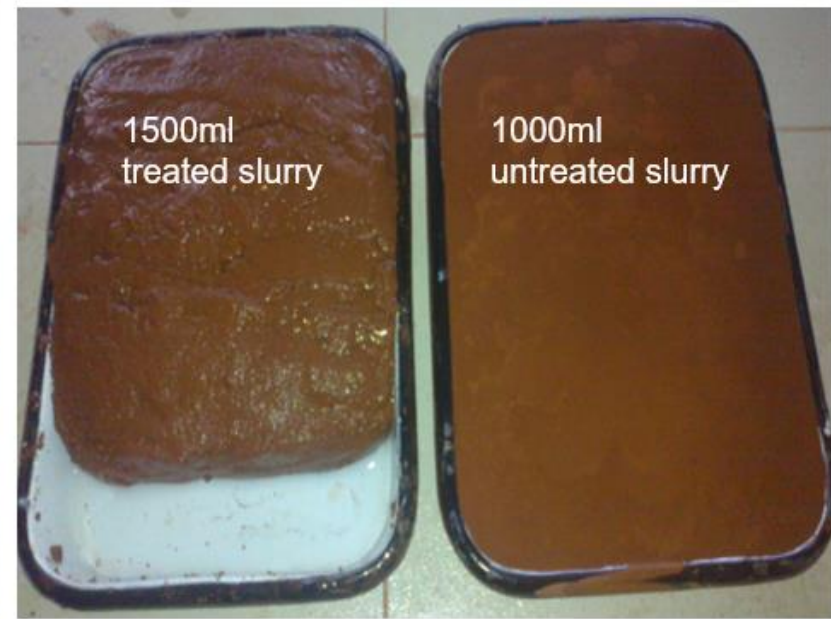

(b)

Figure 8 WaterShed testing. (a) Solids/liquid separation - solids agglomeration and water recovery; and, (b) Consolidation and volume reduction - more solids in less space

\subsection{Phase two - conceptual design and trial objectives}

A conceptual design for a trial was developed with Nalco Water, which commenced in March 2013 (Johns et al. 2012).

The agreed KPI emphasis being on:

- Dewatering the tailings at point of discharge into the pit (target $>60 \%$ solids).

- Quantifying volume of recovered water along with cost-benefit analysis.

- Using the reclaimed water for dust suppression in the first instance until quality can be confirmed suitable for reuse in the process to offset outside water purchases providing savings for the operation.

- Seal the fault lines and fissures within the pit to prevent potential groundwater contamination.

The self-contained trial equipment was set up near the current tailings discharge into the Big Baron Pit (Figures 9 and 10). The equipment was also near the decant water recovery line back to the plant, as a potential water source for polymer dilution. 


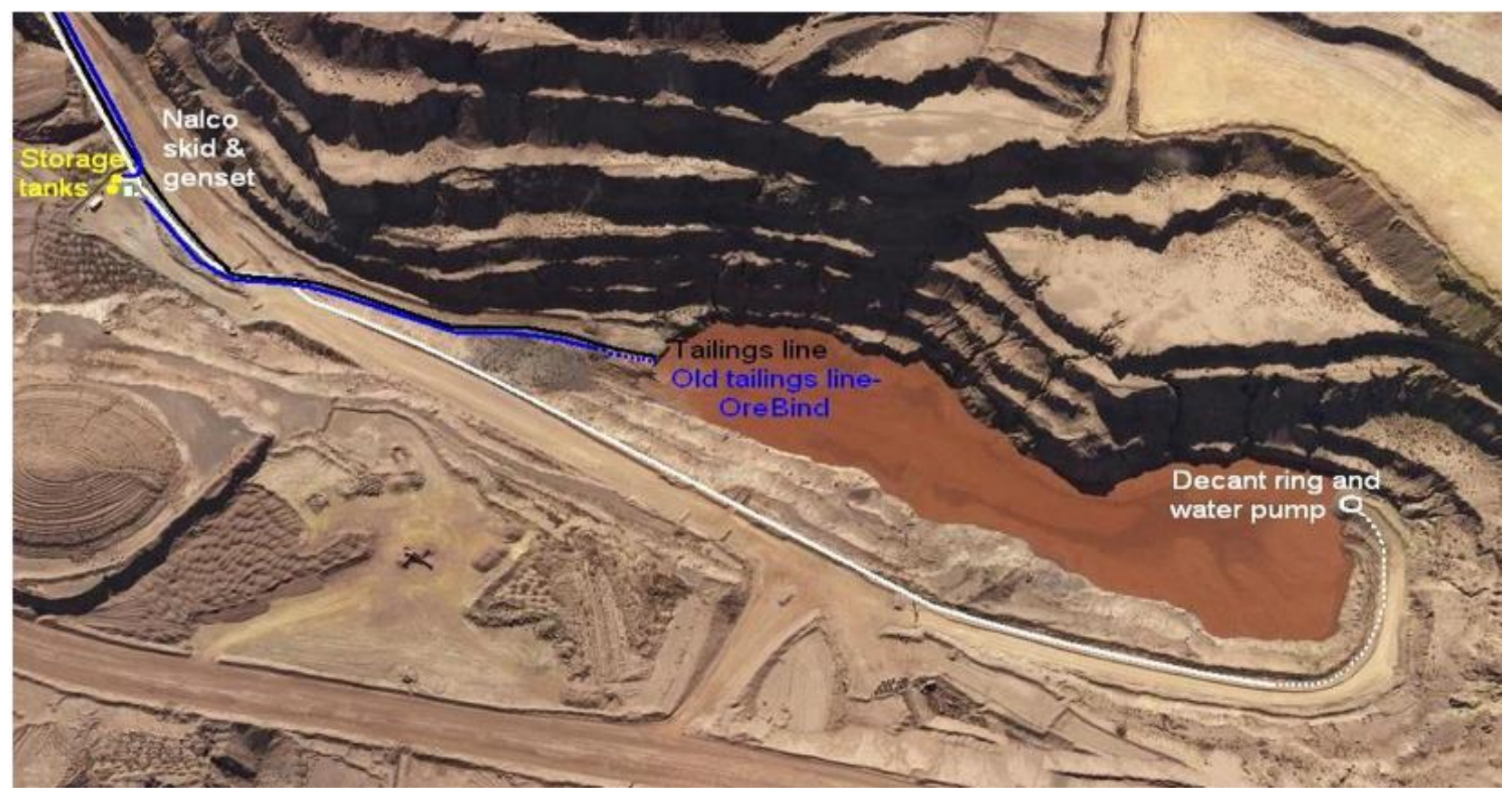

Figure 9 Initial trial set-up layout
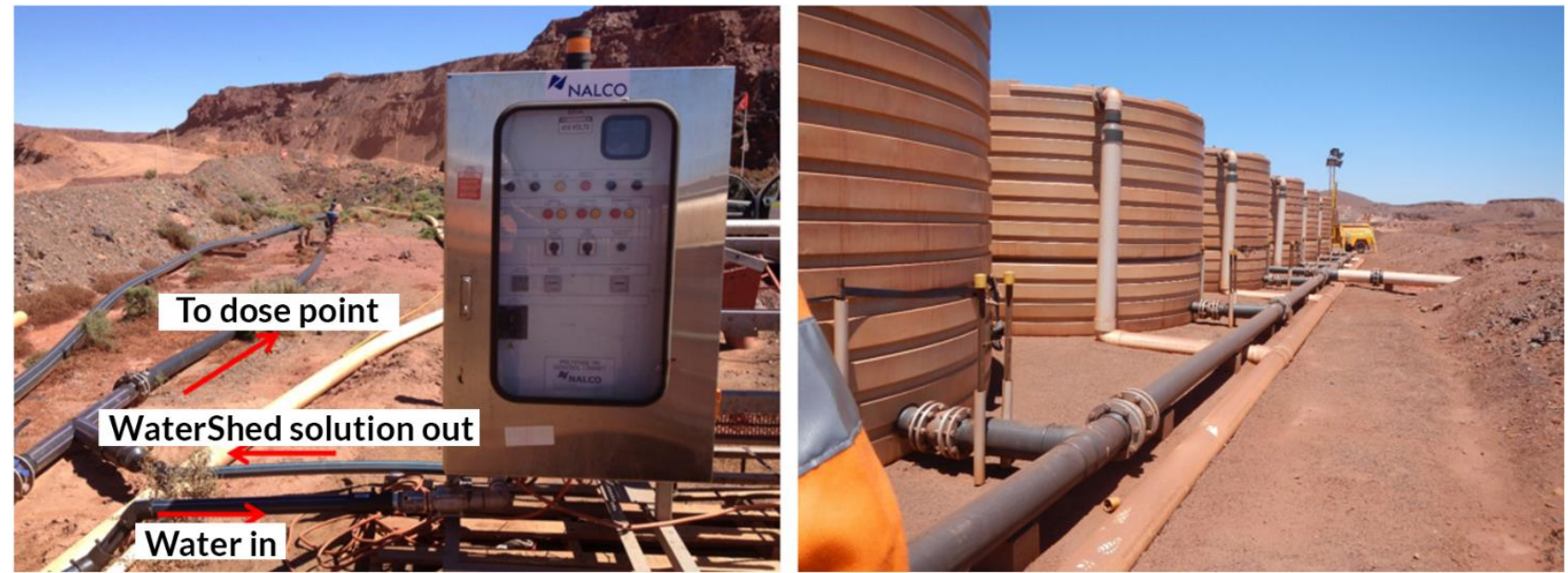

Figure 10 Trial polymer rig and intermediate water tanks used for trial start-up

\subsection{Phase three - field-scale trial}

The initial trial plan was for three weeks of operation. The trial commenced using process water sent from the Prince Pit as no decant water was available in the Big Baron Pit.

Immediately upon chemical addition, free water became liberated from the slurry and began to flow towards the decant area. The first stages of beach formation were also observed (Figure 11).

The results achieved were visually very clear even to those that had doubts about the use of this technology to solve the problems at the Big Baron Pit. 


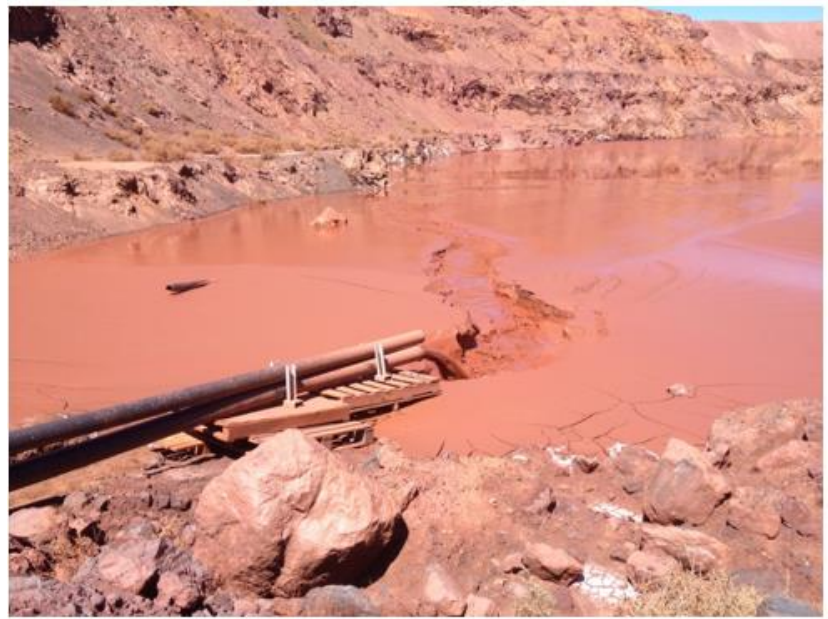

(a)

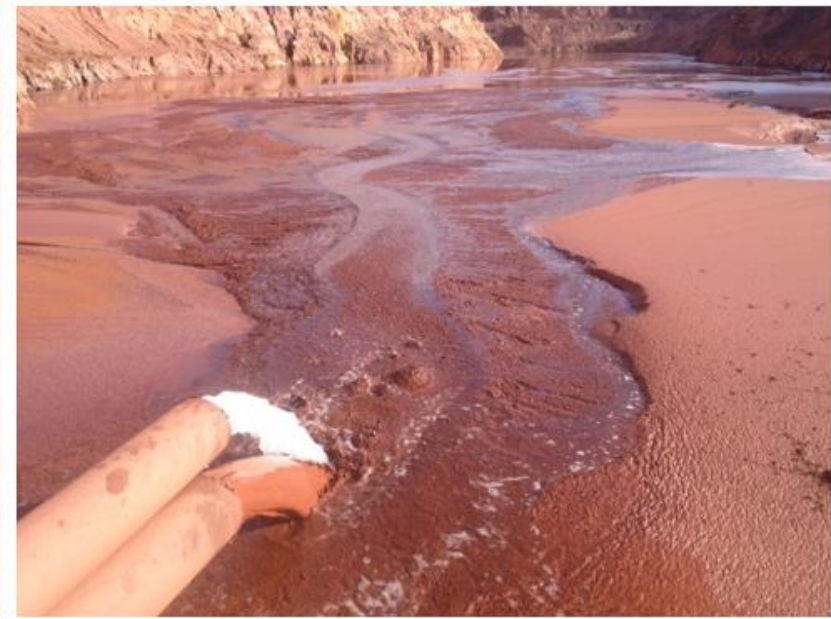

(b)

Figure 11 Before and after photos at trial commencement. (a) Prior to start-up, tailings depositing as smooth paste, no beaching, no water release; and, (b) At start-up, WaterShed process starting, water release occurring

Within two days of the trial commencing, free water in sufficient quantity was observed and recovery at the decant point commenced shortly after. As soon as sufficient decant was available, the total water supply for polymer system operation was drawn from the decant system in closed circuit so the whole application was self-sufficient in terms of water with no negative impact on the greater operations' water balance.

Figure 12 taken from the southern end of the pit (decant end) clearly shows the beach development prior to start-up and at $48 \mathrm{hrs}$ into the trial. It can be seen that a significant beach has been established with dosing and decant water pooling.

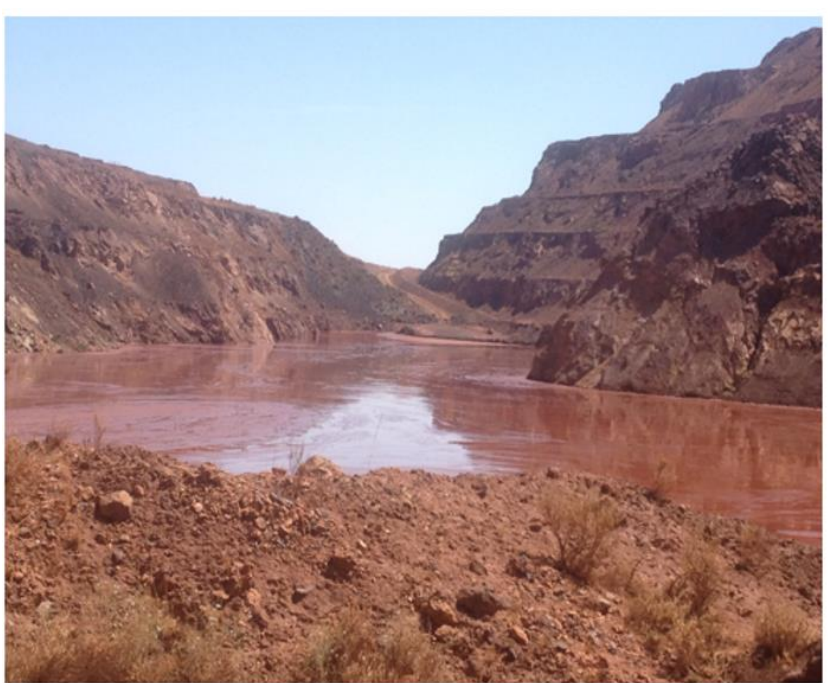

(a)

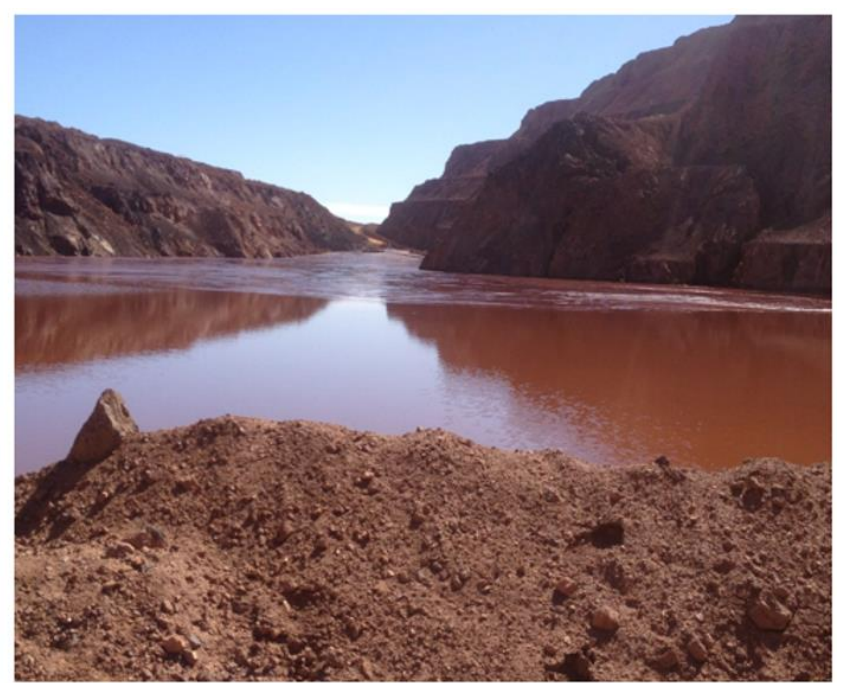

(b)

Figure 12 Photo showing before and after released water at decant end of TSF and beach development. (a) Prior to start-up, 'smooth' consistency, no beach or dewatering; and, (b) At start-up (12 to $48 \mathrm{hrs})$, rapid beach formation, $60 \%+$ water recovery

It was also observed that solids had begun to settle out with the formation of a beach near the discharge point. 
At day three (Figure 13), it was clear that solids were rapidly settling on and building the beach to the point that the drop point needed to be moved back up the access ramp to the pit. This became standard practice as the project developed.

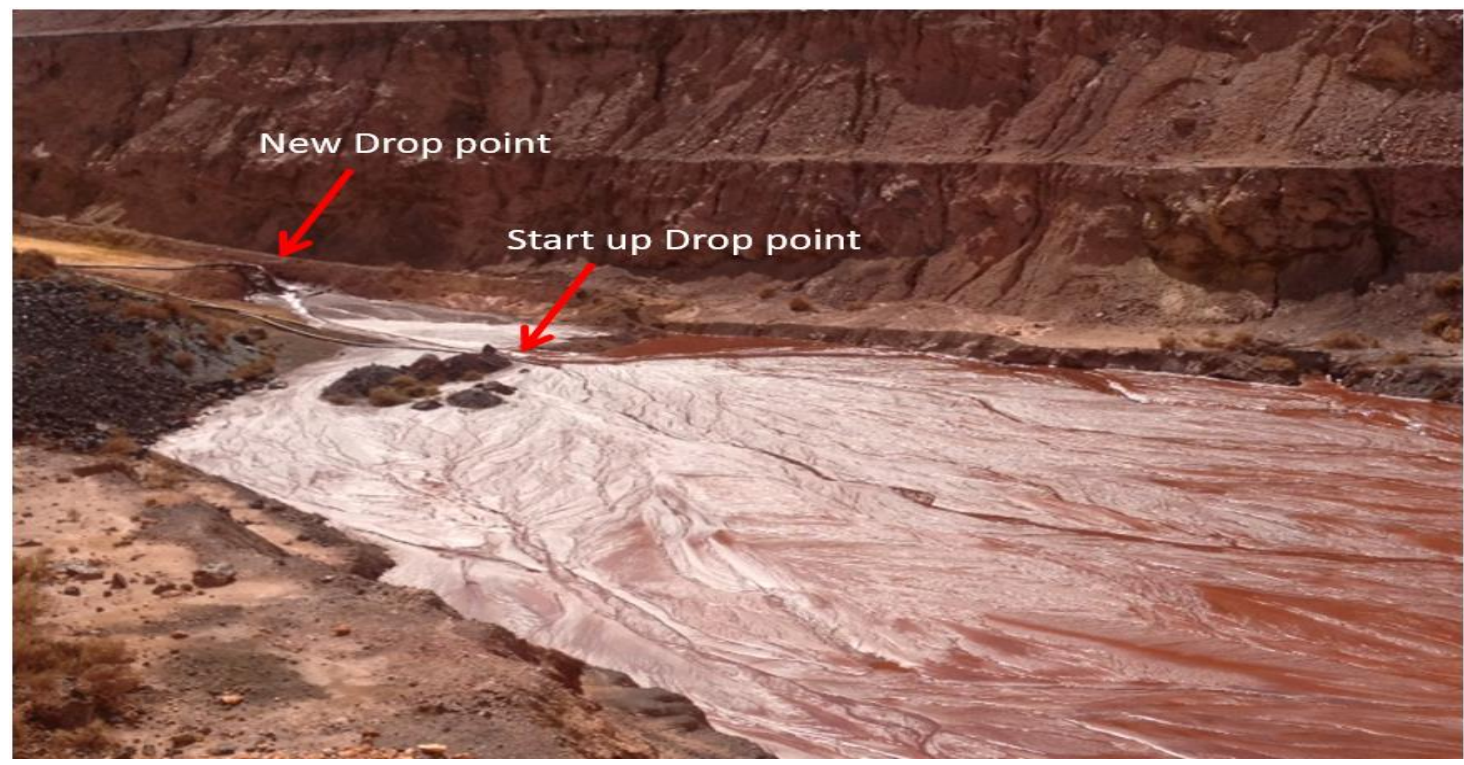

Figure 13 Beach development at day three (drop point raised)

With the water recovery starting at the decant structure, this indicated that the cracks through which water was potentially lost previously had started to seal. Further surveying showed that solids were in fact building up within the TSF. This was backed up by analysis of the surrounding monitoring bores, which showed no increase in the water table, indicating that the cracks in the base of the pit had in fact been sealed.

In the initial weeks of operation, water recovery was confirmed to be of the order of $63 \%$ of TSF inflow. Subsequent ongoing operation under good conditions saw this increase over time with process optimisation.

The Big Baron Pit WaterShed polymer trial was all about water recovery and insuring the pit was sealed. Very little focus was placed on strength or density measurements, however, water recovery was closely monitored and, by calculation, it was determined that the initial $44 \%$ solids slurry being pumped to the pit was increased to an average of $68 \%$ solids by the removal and recovery of $65 \mathrm{~m}^{3} / \mathrm{hr}$ of decant $(63 \%$ average recovery). Allowing for further released water by self-weighting over time and water lost to evaporation it is postulated that final average solids were higher again.

After one month of operation (Figure 14), the beach height at the discharge point had increased by $3 \mathrm{~m}$.

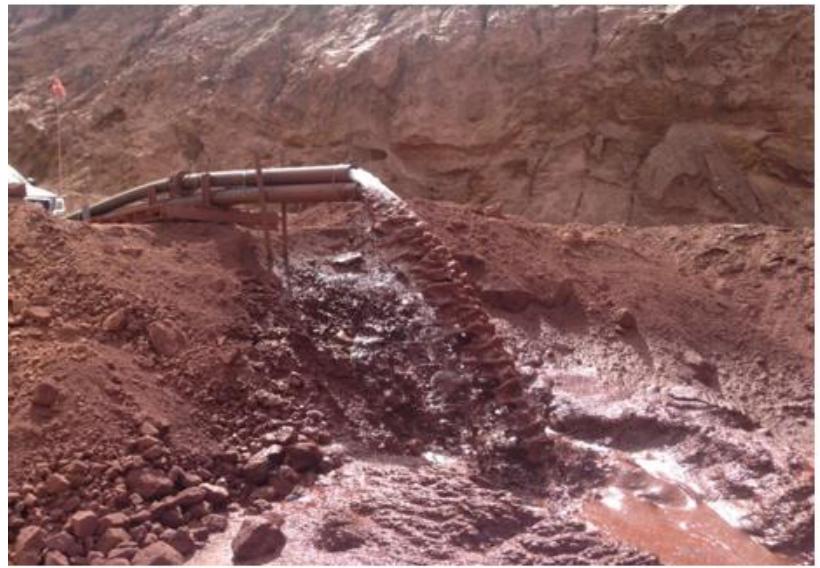

(a)

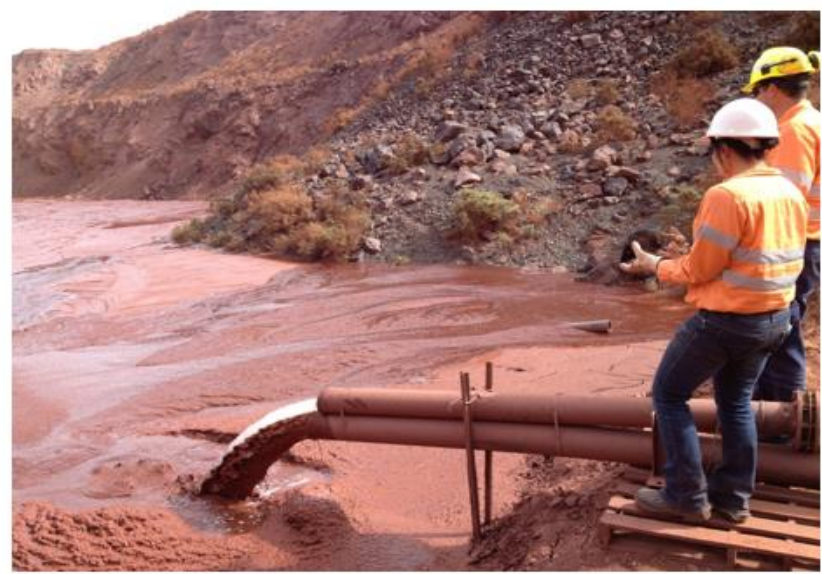

(b)

Figure 14 One month of operation; (a) 15 March 2013; and, (b) 16 April 2013 
WaterShed polymer dosing continued until the void was declared full in September 2014 (Figure 15). During the life of the application a consolidated matrix of dewatered solids was progressively layered down to a depth of approximately $35 \mathrm{~m}$ (RL257-RL222).

The consolidated tailings were still releasing water by self-weighting (late September 2014). The volume released being insufficient to recover was lost to evaporation or provided drinking water for the wild goats that happily tracked across the tailings.
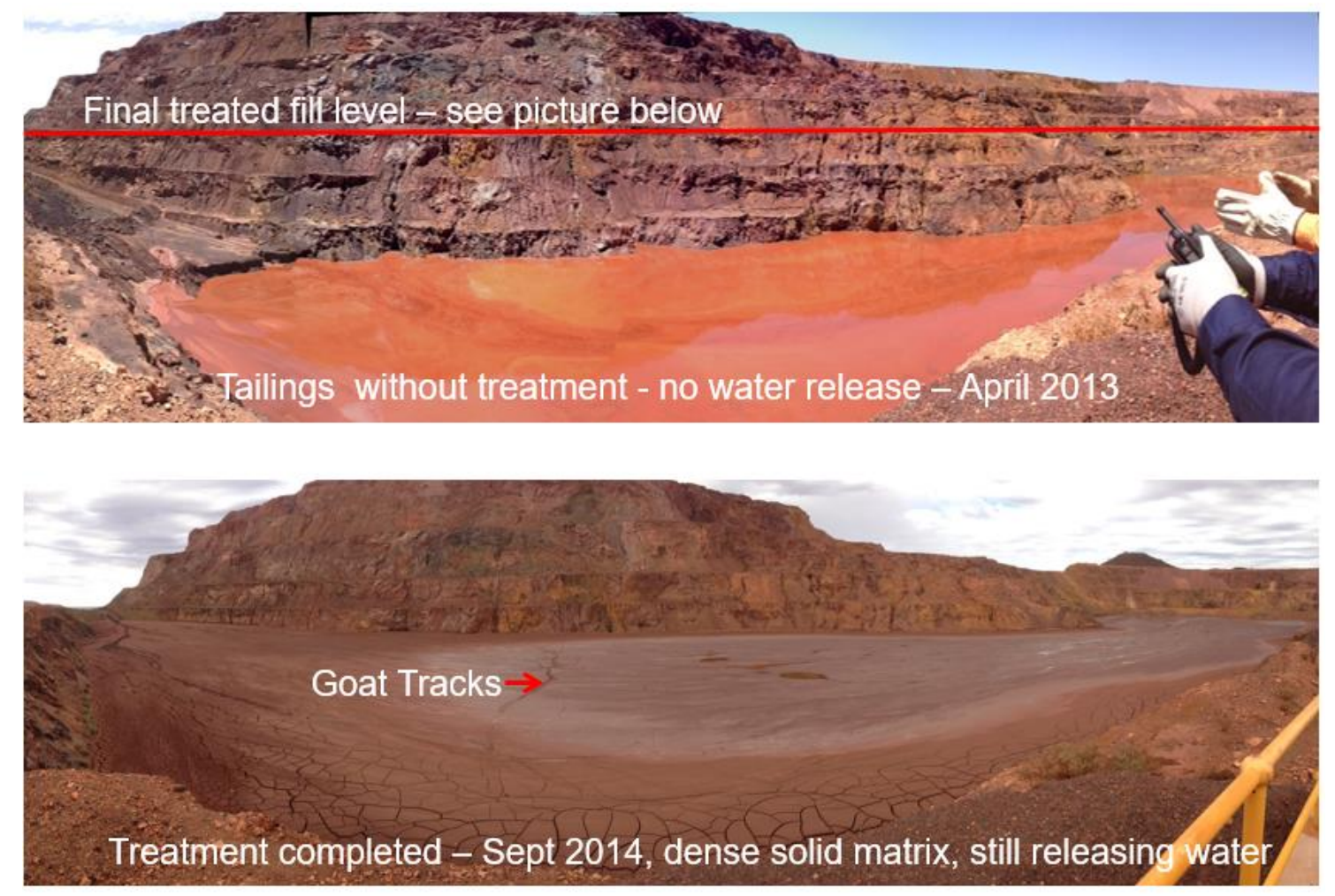

Figure 15 Big Baron Pit at start-up showing final reduced level (RL) fill line in red

\subsection{Phase four - WaterShed polymer in ongoing operations}

The use of WaterShed polymer continued at the Big Baron until the pit reached capacity in September 2014. The success of the application has resulted in this technology becoming an integral part of the SIMEC Mining water management plan.

SIMEC Mining currently operates additional WaterShed applications at:

- Iron Baron - The Prince Pit.

- Iron Knob - Iron Monarch Pit, currently commissioning.

- Iron Duke - large above-ground TSF.

The Iron Duke application on the above-ground TSF has been unique in that the WaterShed technology has been used to assist in converting the design of the TSF to perimeter discharge central decant (PDCD). This has provided solutions to several site-specific issues surrounding the TSF and has enabled the establishment of a solid foundation to support the current upstream wall raises which are underway. This application will likely provide detailed information to support another case study paper in the future.

With each new application, the WaterShed equipment package design (Figure 16) has been upgraded to containerised systems with full telemetry to allow relocation of the systems around the sites as required. Figure 16 shows the current system in operation at the Iron Duke application. 

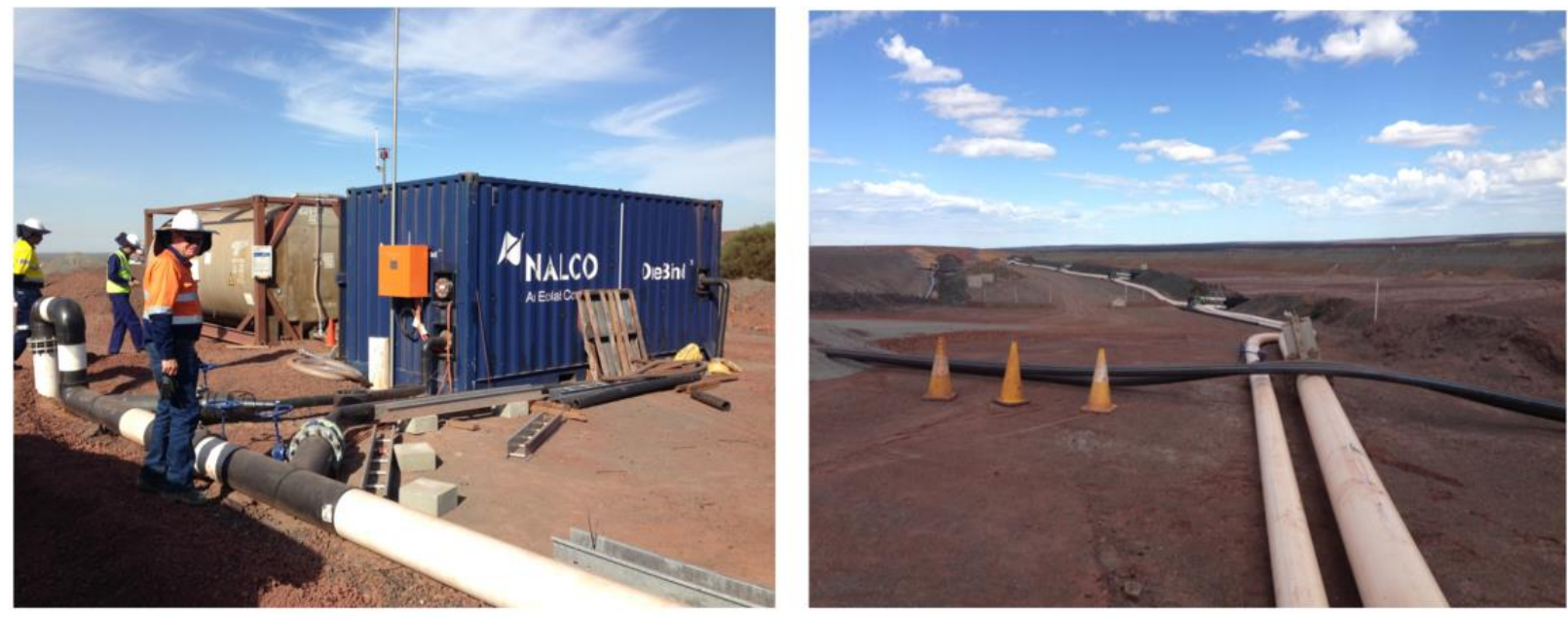

Figure 16 Mobile containerised WaterShed system at Duke TSF

Knowledge gained throughout the Big Baron Pit application has created a high focus on site water management and the use of this technology has been expanded across SIMEC Mining's operations. A clear understanding has been gained that each TSF needs to be viewed individually as techniques used at one location and their impact on the site water balance can and do change as the process develops. Water flow patterns between pits can and often do change dramatically over the course of time as pit levels change. A close focus is required on the management of the tailings operations.

\section{$4 \quad$ Summary and return on investment}

The plant-scale effectiveness of WaterShed polymer technology (previously called OreBind) was tested on a full plant-scale. The trial was initially intended to run for a period of two to three weeks. After the initial success of the trial, the operations team at Iron Baron requested that the trial continues indefinitely.

During the trial, the monitoring of flows, pit levels, bore water levels, water volumes, water quality and WaterShed polymer consumption was something that had to be paid close attention to. The bore levels were of interest to the environmental department as we were expecting to be producing a large amount of water and the management of that was very important to avoid environmental issues.

The plant uses approximately $1,000 \mathrm{~m}^{3} / \mathrm{hr}$ of water in the process. Of this there is approximately $120 \mathrm{~m}^{3} / \mathrm{hr}$ of fresh water addition to make up the total needed. At the time of the trial the price of fresh water from SA Water was approximately AUD $3.50 / \mathrm{m}^{3}$. Prior to the trial, that equated to a cost of AUD 420/hour for fresh water. The cost of recovering water using the WaterShed technology to dewater the tailings over the long-term was calculated to be less than AUD $1.00 / \mathrm{m}^{3}$.

With fresh water costing AUD $3.50 / \mathrm{m}^{3}$, using the WaterShed polymer would save AUD $2.50 / \mathrm{m}^{3}$. If the plant has $90 \%$ availability (329 days a year) and it is expected that $60 \mathrm{~m}^{3} / \mathrm{hr}$ of recovered water can continually offset purchased fresh water, this equates to a savings of AUD 3,600/day and AUD 1,120,000/year in fresh water. To look at the savings in non-financial terms, this equates to a water saving of $1,440 \mathrm{~m}^{3} /$ day or $473,000 \mathrm{~m}^{3} /$ annum. These numbers are considered conservative with decant water recovery often exceeding $60 \mathrm{~m}^{3} / \mathrm{hr}$ as the effects of compressive self-weighting came into play (Owens 2013).

The bulk of SIMEC's mining activities currently takes place on the Eyre Peninsula. There is a finite amount of fresh water available in the region and it is believed that industry is fast approaching the limit of what is available. As such, if a new mine or ore processing facility were to be considered there would be little water available for this. The success of the Iron Baron Pit project confirmed the benefits of the Nalco WaterShed technology, thus widening the scope of options open to SIMEC Mining into the future. The company has demonstrated a commitment to doing the right thing by the community and the environment, which should assist with approvals for future development of operations. 


\section{Acknowledgement}

The successful evaluation of WaterShed polymer in the Big Baron application was the result of a massive team effort comprised of many people all willing to explore new options for process improvement working together in a team environment.

Many departments at SIMEC Mining have worked together to make this happen. Shayne Daniel and his team at Iron Baron Operations have provided nothing but assistance and support.

SIMEC's capital department also enabled much of the infrastructure to happen and Peter Shambrook helped us get through some trying times.

Andrew Graetz and his Lucas Earthmovers for mining operations at Iron Baron have always been accommodating in all our requests and have always helped us solve problems with no issue.

The following people also deserve a special mention: Jesse Wood, Sarah Nicholls, Mike Bannear, Justine Jasper, and the SIMEC Mining technology development team.

Much of this trial would not have been possible without the assistance of the Whyalla Nalco team, with 'on the ground' support from Bill Johns, Claudia Hobart, Dion Travers, Ben Butler and specialist support with WaterShed technology from Mike Bennett.

\section{References}

Bennett, M 2011, Tailings Management - Tailings Thickener Underflow Dewatering, Nalco Water, Whyalla.

Johns, B, Travers, D, Butler, B \& Hobart, C 2012, Nalco Internal Service Report - Tailings Dewatering, Nalco Water, Whyalla.

Owens, B 2013, Dewatering of Tailings, Iron Baron, final year project, Bachelor of Engineering (Metallurgy), University of South Australia, Adelaide. 
